\title{
Tests of changes in the resistance of heating water flow in the home heating system
}

\author{
Bartosz Ciupek ${ }^{1}$, Wojciech $\mathrm{Judt}^{1}$, and Rafat Urbaniak $^{1}$ \\ ${ }^{1}$ Poznań University of Technology, Chair of Thermal Engineering, Piotrowo 3, 60-965 Poznań, Poland
}

\begin{abstract}
The article presents the results of experimental research on the change of resistance of heating water flow in the home heating system under the influence of boiler work configuration changes. For the tests was used the research object in the form of a solid fuel heating boiler with automatic fuel feeding. The research facility was installed in an open-type heating network designed to reproduce the layout of the house heating system. During the tests, boiler operation was simulated for a few selected thermal loads most often found in individual heating. During the tests, the boiler worked with the power of: $10 \%, 30 \%, 50 \%$, $80 \%$ and $100 \%$ of nominal boiler power. For each of the selected options, a series of flow resistance measurements were made using a U-type liquid manometer tube made by researchers. The obtained results of experimental research can be used as an aid in the case of designing home heating networks equipped with a solid fuel boiler.
\end{abstract}

\section{Introduction}

Designing of home heating water hydraulic networks consists in selecting the diameters of pipes and regulating elements with corresponding to the calculated heating parameters [1]. The task of a heating system is to provide the desired amount of heat depending on the heat load of a network and the individual preferences of users. Therefore, in order for the radiators to reach a required heat output with the assumed temperature difference, is necessary to provide for each heater an appropriate mass stream of water. This condition is realized by appropriate adjustment of the installation in the design conditions and in the next step by the operating regulation resulting from the actual hydraulic parameters. In Poland, the calculation method is usually used, consisting in determining the appropriate hydraulic settings and selecting the right pumps and valves for the maximum parameter of the boiler. Assuming that most heating systems are oversized against the actual heat demand, these networks operate in unsuitable conditions. Low pressure and mass flow rate of the heating water contributes to formation of lime scale and rust in a heating system. Based on previous research and analyzes a most heating boilers for solid fuels operate with $30 \%$ of their nominal power within a year. The average heating power of solid fuel heating boilers can vary from $10 \%$ to $80 \%$ depending on the heat load of the appliance.

Authors of a paper analyzed a construction of firetubes boilers for solid fuels used in home heating installations and conducted experimental studies on the impact of changes in water pressure drop in the installation under the influence of changes in a configuration of work [2, 3]. To make a tests, researchers made a testing stand equipped by boiler and heat network.

A scheme of a test stand is shown in figure 1.

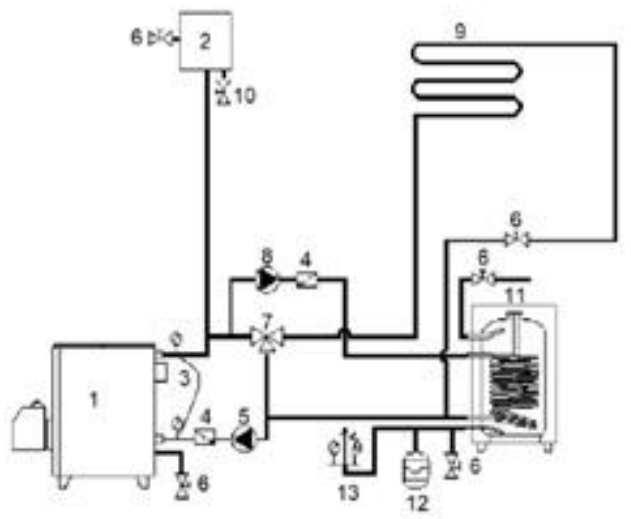

Fig. 1. Scheme of a test stand $-1-$ boiler, $2-$ expansion vessel, 3- u-tube manometer, 4 - check valve, 5 - pump, 6 shut-off valve, 7 - three-way valve, 8 - pump, 9 - heat exchanger, 10 - emergency water drain, 11 - hot water tank, 12 - expansion vessel, 13 - safety valve

Two types of wood pellet boilers ( $25 \mathrm{~kW}$ and $70 \mathrm{~kW}$ ) were used for the tests. The boilers was made by a firetubes convection part in vertical and horizontal configuration. The research objects are shown in figure 2.

The main purpose of the paper was an analysis of a water pressure drops in the heating system under the influence of a change in thermal power of a solid fuel boiler. During the tests was prepared an analysis of the

Corresponding author: bartosz.ciupek@put.poznan.pl 
dependence between the change of a thermal power settings and the obtained pressure drop of the flowing medium. Measurement of pressure drop in water flow is a simple way to estimate basic parameters of fluid flow, without the need for long-term analyzes, often based on data not verified by the experiment $[4,5]$. Experimental studies of solid fuel heating boilers and heating systems are widely present in research on modern heating installations [6, 7]. Obtained results and characteristics can be used by designers to optimize boilers design in terms of the flow of the heating fluid through convection parts.
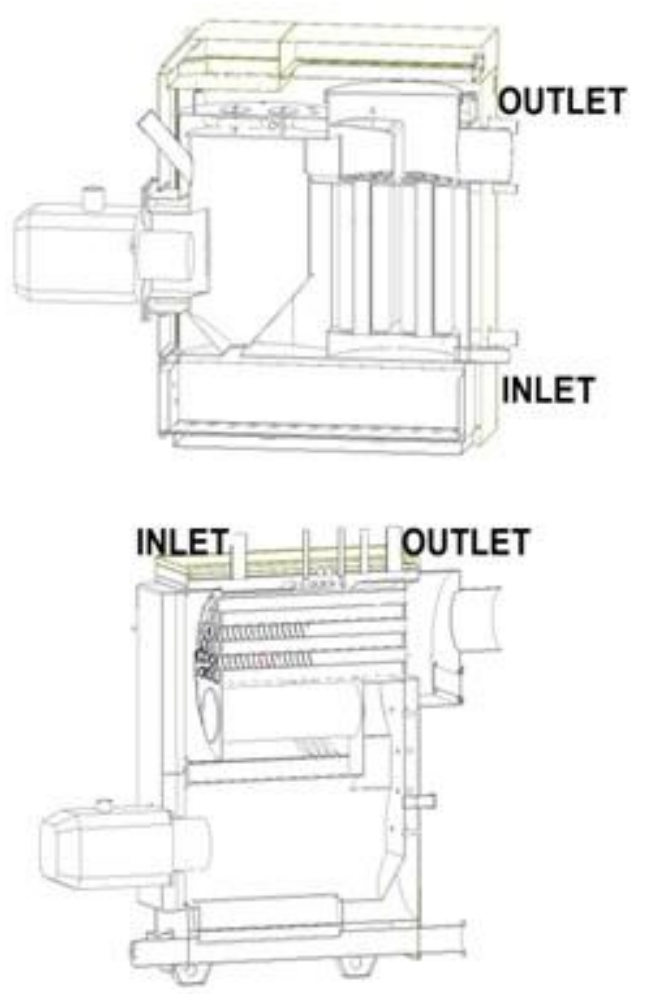

Fig. 2. Cross-section of the boiler $25 \mathrm{~kW}$ and boiler $70 \mathrm{~kW}$

\section{Analysis and modeling}

Authors of article assumed, that a temperature of water flow, which are leaving a heating boiler is around a 344 $\mathrm{K}$. The minimal temperature of water in the outlet of the heat exchanger was assumed to equal a $324 \mathrm{~K}$. The minimal temperature difference of water in the return to boiler was set on $\Delta \mathrm{T}=10 \mathrm{~K}$ and $20 \mathrm{~K}$. The mass flow rate of water was computed from equation 1 .

$$
\dot{M}=\frac{\dot{W}}{C_{w} \cdot\left(T_{1}-T_{2}\right)}
$$

According to equation 1, during the tests, the mass flow rate of water was adjusted to achieve the assumed boiler power and the temperature difference between the supply and return of the boiler and heat exchanger.

Regulation of the water mass flow for individual temperature differences was made by calculating the minimum pump capacity for tested power of boiler. The minimum pump capacity was computed from equation 2 .

$$
\dot{V}_{p}=\frac{1.1 \cdot \dot{W}}{C_{w} \cdot\left(T_{1}-T_{2}\right) \cdot \rho_{w}}
$$

To calculate the pressure generated by the pump was used equation 3 .

$$
\Delta p_{p}=0.9 \cdot \dot{V}_{p} \cdot \Delta \rho_{w} \cdot g
$$

The total active pressure of the installation was calculated by equation 4 .

$$
\Delta p_{n}=\Delta p_{p}+0.75 \cdot \Delta \rho_{w} \cdot g \cdot \Delta_{H}
$$

U-tube liquid manometer was used to measure the pressure drop in the boiler circuit. To calculate the pressure drop was used equation 5.

$$
\Delta p=\rho_{w} \cdot g \cdot \Delta_{H}
$$

Alternatively, the pressure losses caused by the local resistance can be determined on the basis of the flow coefficient $\mathrm{K}_{\mathrm{v}}$. The higher the value is assumed by the flow coefficient $\mathrm{K}_{\mathrm{v}}$, the smaller the resistance. This is the inverse relationship compared to coefficient of fluid resistance $\zeta$. The equation 6 was used to calculate the flow coefficient $\mathrm{K}_{\mathrm{v}}$.

$$
K_{v}=\frac{\dot{M}}{\sqrt{\Delta H}}
$$

\begin{tabular}{|c|c|c|}
\hline \multirow{2}{*}{$\begin{array}{c}\text { Boiler } \\
\text { power (\%) }\end{array}$} & \multicolumn{2}{|c|}{$\begin{array}{c}\text { Water flow rate } \\
\left(\mathrm{m}^{3} / \mathrm{h}\right)\end{array}$} \\
\hline & $\Delta \mathrm{T}=20^{\circ} \mathrm{C}$ & $\Delta \mathrm{T}=10^{\circ} \mathrm{C}$ \\
\hline 10 & 0.11 & 0.22 \\
\hline 30 & 0.32 & 0.65 \\
\hline 50 & 0.54 & 1.06 \\
\hline 80 & 0.86 & 1.72 \\
\hline 100 & 1.08 & 2.15 \\
\hline $\begin{array}{c}\text { Boiler } \\
\text { power (\%) }\end{array}$ & \multicolumn{2}{|c|}{$\begin{array}{l}\text { Water pressure drop } \\
\qquad(\mathrm{Pa})\end{array}$} \\
\hline & $\Delta \mathrm{T}=20^{\circ} \mathrm{C}$ & $\Delta \mathrm{T}=10^{\circ} \mathrm{C}$ \\
\hline 10 & 537 & 1467 \\
\hline 30 & 596 & 1496 \\
\hline 50 & 762 & 1633 \\
\hline 80 & 1095 & 1946 \\
\hline 100 & 1379 & 2278 \\
\hline $\begin{array}{c}\text { Boiler } \\
\text { power (\%) }\end{array}$ & \multicolumn{2}{|c|}{ Flow coefficient $\left(\mathrm{m}^{3} / \mathrm{h}\right)$} \\
\hline & $\Delta \mathrm{T}=20^{\circ} \mathrm{C}$ & $\Delta \mathrm{T}=10^{\circ} \mathrm{C}$ \\
\hline 10 & 0.005 & 0.006 \\
\hline 30 & 0.013 & 0.017 \\
\hline 50 & 0.019 & 0.027 \\
\hline 80 & 0.026 & 0.039 \\
\hline 100 & 0.029 & 0.045 \\
\hline
\end{tabular}

\section{Results and discussion}

Table 1 shows the results for a $25 \mathrm{~kW}$ boiler with a vertical configuration of fire-tubes.

Table 1. Hydraulic parameters of a water flow for $25 \mathrm{~kW}$ firetubes boiler. 
The experimental tests carried out were used to perform calculations and analyzes of the hydraulic resistance of the boiler water flow through the tested boilers. The results of the water flow, pressure drop and flow coefficient in correlation to the thermal power of the boiler are presented in the tables below.

Table 2 shows the results for a $70 \mathrm{~kW}$ boiler with a vertical configuration of fire-tubes.

Table 2. Hydraulic parameters of a water flow for $70 \mathrm{~kW}$ firetubes boiler.

\begin{tabular}{|c|c|c|}
\hline \multirow{2}{*}{$\begin{array}{c}\text { Boiler } \\
\text { power (\%) }\end{array}$} & \multicolumn{2}{|c|}{$\begin{array}{l}\text { Water flow rate } \\
\left(\mathrm{m}^{3} / \mathrm{h}\right)\end{array}$} \\
\hline & $\Delta \mathrm{T}=20^{\circ} \mathrm{C}$ & $\Delta \mathrm{T}=10^{\circ} \mathrm{C}$ \\
\hline 10 & 0.30 & 0.60 \\
\hline 30 & 0.90 & 1.81 \\
\hline 50 & 1.50 & 3.01 \\
\hline 80 & 2.41 & 4.82 \\
\hline 100 & 3.01 & 6.02 \\
\hline $\begin{array}{c}\text { Boiler } \\
\text { power }(\%)\end{array}$ & \multicolumn{2}{|c|}{$\begin{array}{l}\text { Water pressure drop } \\
(\mathrm{Pa})\end{array}$} \\
\hline & $\Delta \mathrm{T}=20^{\circ} \mathrm{C}$ & $\Delta \mathrm{T}=10^{\circ} \mathrm{C}$ \\
\hline 10 & 479 & 1066 \\
\hline 30 & 772 & 1594 \\
\hline 50 & 938 & 1838 \\
\hline 80 & 1007 & 1916 \\
\hline 100 & 1046 & 1956 \\
\hline $\begin{array}{c}\text { Boiler } \\
\text { power }(\%)\end{array}$ & \multicolumn{2}{|c|}{ Flow coefficient $\left(\mathrm{m}^{3} / \mathrm{h}\right)$} \\
\hline & $\Delta \mathrm{T}=20^{\circ} \mathrm{C}$ & $\Delta \mathrm{T}=10^{\circ} \mathrm{C}$ \\
\hline 10 & 0.014 & 0.018 \\
\hline 30 & 0.032 & 0.045 \\
\hline 50 & 0.049 & 0.070 \\
\hline 80 & 0.076 & 0.110 \\
\hline 100 & 0.093 & 0.136 \\
\hline
\end{tabular}

The obtained waveforms for flow velocity and pressure drop distribution are presented in the graphs below. Figure 3 shows the results of the flow and distribution of pressure drop as a function of power for the $25 \mathrm{~kW}$ boiler.

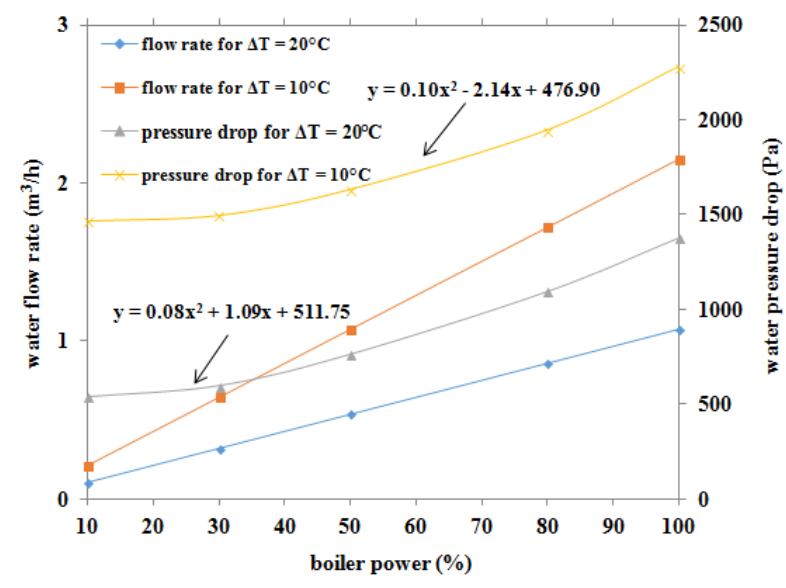

Fig. 3. Flow and pressure drop in function of power for the 25 $\mathrm{kW}$ boiler

Figure 4 shows the results of the flow and distribution of pressure drop as a function of power for the $70 \mathrm{~kW}$ boiler.

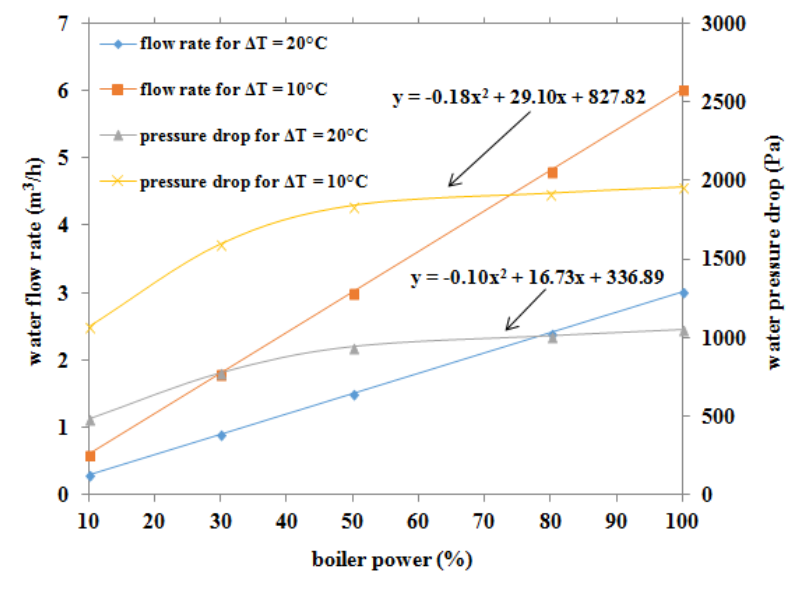

Fig. 4. Flow and pressure drop in function of power for the 70 $\mathrm{kW}$ boiler

The tests show that with the change of boiler operation settings, the parameters of the hydraulic resistance for water flow in the heating system change. The results range from about $480 \mathrm{~Pa}$ to about $2300 \mathrm{~Pa}$ differential pressure. The flow rate ranges from 0.005 $\mathrm{m} 3 / \mathrm{h}$ to $0.136 \mathrm{~m} 3 / \mathrm{h}$. The results show significant hydraulic resistances for high heating medium flow velocity. It results from the technical parameters of modern heating installations and from the complicated construction of the water part of boilers. The tests show that as the water flow rate increases in the hydraulic system a flow resistance increases. In addition, the dependence of the growth of hydraulic resist in relation to a construction of the boiler heat exchanger and a thermal power of the system was observed. The next maintenance is the analogical arrangement of the course of the heating water pressure drop in relation to the varying boiler power. In addition, higher hydraulic resistances were observed for the system working with a smaller temperature difference for the boilers output and input. In the case of vertical and horizontal configuration of the fire-tubes convection part it can be seen that as the boilers power increases, the flow coefficient increases, which confirms the favourable operating parameters of the heating device for the rated power.

\section{Conclusions}

Realized experimental research allowed to show the influence between configuration of work to hydraulic resistance of water flow in boilers. Information, about more advanced calculations, focused on water flow and pressure drop in heat devices can be found in papers [8-11].

Realized numerical calculations verified thesis of research. Experimental and numerical analysis showed, that an heat water flow in analyzed constructions is dependent of configuration of device power parameter. Realized research showed an characteristic flow resistance curves for typical boiler designs.

Experimental and numerical research are a good solution for a water pressure drop tests [12] not only in boiler design but also in the design of whole heat 
networks. The results of experimental research can be used as an aid in the case of designing heating boilers and home heating networks.

The research was financed by the Poznan University of Technology financial resources for the statutory activity.

\section{References}

1. S.R. Yang, Z.M. , G.Y. Wang, He, Engineering Fluid Mechanics, Petroleum Industry Press, 7 , 121 (2006)

2. B. Ciupek, R. Urbaniak, Ciepłownictwo, Ogrzewnictwo, Wentylacja, 49, 519 (2018)

3. S. Kruczek, Boilers - Constructions and calculations (Oficyna Wydawnicza Politechniki Wrocławskiej, Wrocław, 2001)

4. H.Y. Zhao, X.S. Jia, S.M. Yang, Scientific Technology and Engineering, 9, 5238 (2009)

5. D. Bedakes, D.D. Knight, Journal of Fluids Engineering, 114, 119 (1992)

6. Z.D. Zhou, C.Z. Wei, M.Y. Sun, Scientific Technology and Engineering, 12, 7983 (2012)

7. J.Y. Zhao, Y.J. Zhang, X.M. Zheng, Journal of Beijing Institute of Civil Engineering and Architecture, 20, 1 (2004)

8. B. Jorgen, M. Tor-Goran, ASHRAE Transaction, 106, 359 (2000)

9. J. Chen, H. Lü, X. Shi, Z. Delan, W. Wene, Transactions of the CSAE, 28, 73 (2012)

10. L. Li, Y. Li, J. Huang, H. Zhongzhi, Journal of Hydraulic Engineering, 32, 49 (2001)

11. G. Mao, J. Zhang, W. Cheng, H. Yunjin, P. Liuping, C. Lifen, Hydroelectric Power Journal, 24, 17 (2005)

12. D. Taler, The dynamics of tubular heat exchangers (Wydaw. Nauk.-Dydakt. AGH, 2009) 